\title{
ANALISIS DEVIASI ALAT UKUR LAJU ALIRAN PADA UNTAI FASSIP-01 DAN FASSIP-02
}

\author{
Try Hutomo Putra ${ }^{1}$, Giarno $^{2}$, Sumantri Hatmoko ${ }^{2}$, G.B. Heru K${ }^{2}$, Mulya Juarsa, ${ }^{2, *}$ \\ ${ }^{1}$ Mahasiswa Departemen Fisika, FMIPA Universitas Padjadjaran, Bandung \\ Kampus UNPAD, Jatinangor, Sumedang 45363 \\ ${ }^{2}$ Pusat Teknologi dan Keselamatan Reaktor Nuklir Badan Tenaga Nuklir Nasional \\ Gedung 80 Kawasan PUSPIPTEK, Setu, Tangerang Selatan 15310 \\ *email: juars@batan.go.id
}

\begin{abstract}
ABSTRAK
ANALISIS DEVIASI ALAT UKUR LAJU ALIRAN PADA UNTAI FASSIP-01 DAN FASSIP-02. Pengembangan sistem keselamatan pasif dengan mengandalkan kerja natural circulation menggunakan Untai uji FASSIP-01 dan FASSIP-02 memerlukan alat ukur dengan spesifikasi laju aliran rendah. Salah satu jenis alat ukur pendingin adalah Ultrasonic Flowmeter TUF-2000M (US-FM) yang perlu dipersiapkan untuk penggunaan pada eksperimen sistem keselamatan pasif. Tujuan penelitian adalah untuk menentukan deviasi pengukuran laju aliran antara US-FM dengan alat ukur lainnya. Eksperimen dilakukan dengan mengukur laju aliran pada Untai uji BETA menggunakan flowmeter tersebut dengan konfigurasi laju alir yang berbeda yaitu 0 - 100 LPM, 0 - 50 LPM dan 0 - 20 LPM. Hasil perbandingan pengukuran pada sensor elektromagnetik didapat nilai deviasi 6,32 \% untuk konfigurasi 0 - 100 LPM, 2,12 \% untuk konfigurasi 0 - 50 LPM, dan 1,16 \% untuk konfigurasi 0 - 20 LPM. Data untuk melakukan karakterisasi dapat diperoleh pula ketika mengukur laju aliran dengan membaca nilai arus yang bekerja pada sensor pada flowmeter. Dari hasil karakteristika linear terhadap semua flowmeter tersebut terlihat bahwa semakin rendah formasi pengukuran maka diperoleh nilai deviasi juga semakin kecil.
\end{abstract}

Kata kunci : sistem pendingin pasif, alat ukur laju aliran, deviasi, FASSIP-01, FASSIP-02

\section{ABSTRACT}

ANALYSIS ON THE DEVIATION OF FLOW RATE DEVICE IN THE FASSIP-01 AND FASSIP-02 TEST LOOP. The development of a passive safety system that relies on natural circulation using the FASSIP-01 and the FASSIP-02 test loop requires a measuring device with a low flow rate specification. One of such flow meters is the Ultrasonic Flowmeter TUF-2000M (US-FM) which needs to be prepared for conducting experiments in the passive safety system. The purpose of this work is to determine the deviation of the flow rate measurement between US-FM and other measuring instruments. The experiment was carried out by measuring the flow rate in the BETA test loop using the flowmeter with different flow rate, which are 0 - 100 LPM, 0 - 50 LPM and 0 - 20 LPM. The comparison of measurements on electromagnetic sensors results in a deviation value of $6.32 \%$ for configurations of 0 - 100 LPM, $2.12 \%$ for configurations $0-50$ LPM, and $1.16 \%$ for configurations 0-20 LPM. Data for characterization can also be obtained when measuring the flow rate by reading the current value that works on the sensor loop on the flow meter display. From the linear characteristics of all flow meters, it shows that the lower of formation of the measurement the lesser is the deviation.

Keywords: passive cooling system, flow rate device, deviation, FASSIP-01, FASSIP-02 


\section{PENDAHULUAN}

Pembangunan PLTN di Indonesia masih belum terwujud karena banyak menuai pro dan kontra. Sebenarnya Indonesia memiliki 3 reaktor, namun sampai saat ini hanya berfungsi sebagai reaktor riset yang bearada di Bandung, Serpong dan Yogyakarta yang dikelola oleh BATAN. Adanya PLTN masih menjadi momok bagi sebagian warga, ditambah dengan kecelakaan reaktor Fukushima Daiichi pada tahun 2011 yang disebabkan oleh gempa dengan kekuatan 9 Skala Ritcher (SR), dan tsunami dengan ketinggian 14-15 meter. Keadaan tersebut terus menjadikan reaktor tidak kunjung mendingin karena sistem pendingin aktif (pompa sirkulasi) padam akibat generator yang terendam oleh tsunami dan akhirnya menyebabkan lelehnya teras reaktor. Kondisi tersebut memicu terlepasnya material radioaktif ke lingkungan setelah terjadinya ledakan gas Hidrogen yang diakibatkan kelongsong (cladding) bahan bakar gosong (burn-out) dan bereaksi dengan air sehingga membentuk gas Hidrogen lalu gas Hidrogen tersebut bereaksi dengan Oksigen dan menimbulkan ledakan ${ }^{[1]}$. Kejadian tersebut menyebabkan trauma psikis bagi warga Fukushima dan juga menyebabkan penolakan masyarakat Indonesia terhadap pembangunan PLTN semakin menjadi-jadi.
Kecelakaan yang terjadi di Fukushima itu membuat para peneliti di seluruh penjuru dunia mengembangkan teknologi sistem pendingin pasif (passive cooling system) agar dapat membantu mendinginkan reaktor yang panas karena sisa peluruhan (decay heat) ketika sistem aktif mati. Oleh karena itu penelitian ini menunjang penelitian - penelitian lainnya terkait sistem pendingin pasif pada reaktor nuklir. Terdapat dua jenis fasilitas penelitian untuk simulasi sistem pengindingin pasif yang sedang dikembangkan yaitu untai uji FASSIP-01 dan FASSIP-02. FASSIP (FAsilitas Simulasi SIstem Pasif) dikembangkan di Laboratorium Termohidrolik Pusat Teknologi dan Keselamatan Reaktor Nuklir di Serpong ${ }^{[2,3]}$.

Kegiatan penelitian yang dilakukan adalah untuk memahami fenomena aliran sirkulasi alam (natural circulation) pada model sistem pendingin pasif baik dari untai uji FASSIP-01 dan FASSIP-02 yang memerlukan kehandalan sistem pengukur laju aliran. Terdapat empat jenis model alat ukur laju aliran yang telah ada di laboratorium termohidrolika, yaitu model kincir (wheel), elektromagnetik, magnetik dan ultrasonik. Masing-masing alat ukur aliran tersebut memerlukan karakterisasi, kalibrasi dan penentuan nilai deviasi dimana hasil pengukurannya akan digunakan untuk 
memperkuat hasil perhitungan berdasarkan data eksperimen. Sehingga, penelitian ini difokuskan pada penentuan nilai deviasi dari masing-masing alat ukuran aliran tersebut.

\section{TEORI}

Untai uji FASSIP-01 dan FASSIP-02 adalah fasilitas untuk eksperimen sistem pendingin pasif yang berdasarkan pada fenomena natural circulation (sirkulasi alam). Sirkulasi alam merupakan proses perputaran fluida secara kontinyu dan tanpa adanya energi dari luar. Sirkulasi alam didasari oleh gaya bouyancy dan gaya gravitasi. Suatu fluida yang dipanaskan pada temperatur tertentu maka akan mengalami kenaikan temperatur dan kemudian akan mengalami gaya bouyancy atau gaya apung ke atas (menuju ke pendingin) dikarenakan rapat massa nya menjadi lebih kecil daripada rapat massa semula. Uap air tersebut mengalir, namun semakin lama temperaturnya mulai turun karena tidak mendapat panas dan kemudian masuk ke pendingin, disini uap air tersebut mengalami kondesasi, sehingga titik uap air tersebut kembali menjadi air dengan rapat massa yang lebih berat, dengan demikian air turun kebawah dengan gaya gravitasi lalu masuk ke sistem pemanas lagi, begitu seterusnya ${ }^{[4]}$. Studi awal tentang pola aliran seperti itu, dimulai dengan analisis Reyleigh yang mana membahas mengenai stabilitas cairan ketika cairan berhenti sejenak dan mulai bergerak karena gradien garis suhu ke arah gaya tubuh

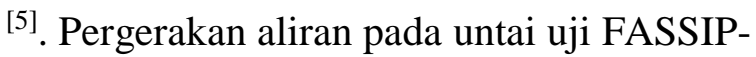
01 dan FASSIP-02 terdapat dua gaya yang berperan pada saat adanya aliran yaitu gaya apung atau gaya ke atas dan gaya gravitasi. Gaya apung adalah gaya dari fluida yang terjadi karena mengalami perubahan massa jenis dari benda atau pun partikel fluida sehingga massa jenisnya menjadi semakin kecil dan menyebabkan ada gaya keatas. Gaya gravitasi yaitu sebuah gaya yang mengarah ke pusat bumi atau ke bawah yang diakibatkan oleh benda yang bermasa yang tertarik oleh massa bumi ${ }^{[6]}$. Tentu saja ada parameter yang harus diperhatikan saat menghitung laju aliran didalam pipa pada untai uji FASSIP-02. Berikut ini rumus yang digunakan untuk menghitung laju aliran pada untai uji FASSIP-01 dan FASSIP-02 [7].

$v=\frac{-64 \mu L \pm \sqrt{64 \mu L^{2}+8 g H K \bar{\rho}\left(\rho_{c}-\rho_{h}\right) D^{4}}}{2 \bar{\rho} K D^{2}}$

Dengan $\boldsymbol{v}(\mathrm{m} / \mathrm{s})$ adalah laju aliran, $\boldsymbol{\mu}(\mathrm{kg} / \mathrm{m} . \mathrm{s})$ adalah viskositas air, $\boldsymbol{L}$ adalah total panjang pipa, $\boldsymbol{g}\left(\mathrm{m} / \mathrm{s}^{2}\right)$ adalah percepatan gravitasi bumi, $\boldsymbol{H}(\mathrm{m})$ adalah perbedaan ketinggian WCT dan WHT, $\boldsymbol{K}$ adalah loss coefficient, $\boldsymbol{\rho}$ $\left(\mathrm{kg} / \mathrm{m}^{3}\right)$ adalah rapat massa fluida, dan $\boldsymbol{D}(\mathrm{m})$ adalah diameter pipa.

Selain dengan menggunakan estimasi, laju aliran dapat diukur dengan menggunakan sensor, mulai dengan menggunakan sensor turbin (wheel), 
elektromagnetik, magnetik, ultrasonik, dan juga masih banyak yang lainnya. Pada penelitian ini digunakan sensor ultrasonik. Prinsipnya adalah mendeteksi frekuensi atau pergeseran fasa yang disebabkan oleh aliran fluida di dalam media. Kecepatan efektif suara dalam fluida bergerak sama dengan kecepatan suara relatif terhadap medium ditambah kecepatan fluida terhadap sumber suara. Dengan demikian, gelombang suara yang menyebar ke upstream akan memiliki kecepatan efektif yang lebih kecil, sementara suara yang menyebar downstream akan memiliki kecepatan efektif yang lebih tinggi. Karena perbedaan antara dua kecepatan adalah dua kali dari kecepatan fluida, mengukur perbedaan kecepatan upstreamdownstream memungkinkan kita untuk menentukan kecepatan aliran.

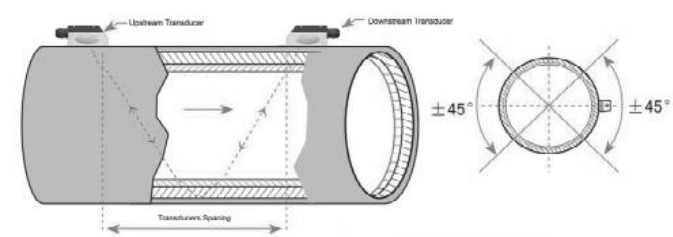

Gambar 1. Ultrasonic flowmeter dan posisi dari kristal transmitter-receiver pada $\operatorname{aliran}^{[8]}$

Gambar 1 merupakan dua transducer ultrasonik yang dipasang pada pipa dengan menggunakan $V$-method. Metode ini sering digunakan untuk pengukuran sehari-hari dan juga penggunaan metode ini jika diameter dalam pipa adalah dari $15 \mathrm{~mm}$ hingga 200 mm. Metode ini juga bisa disebut mode reflective $e^{[8]}$. Karena prinsip kerja dari setiap sensor adalah berbeda, maka dari itu akan terjadi perbedaan pengukuran. Maka analisis deviasi setiap sensor diperlukan untuk pengukuran laju aliran pada Untai FASSIP01 dan Untai FASSIP-02.

\section{METODE}

Penelitan untuk menentukan karakteristik flowmeter ultrasonik memerlukan objek sebagai media untuk mengukur laju aliran, yaitu untai uji BETA yang telah terpasang pompa dengan frekuensi yang dapat divariasikan. Untai uji BETA dapat dilihat pada Gambar 2. Pipa yang terpasang pada untai uji BETA di bagian pemasangan flowmeter ultrasonik adalah pipa SS 304 yang memiliki diameter 33,4 mm. Laju aliran yang mengalir melewati sensor elektromagnetik dan ultrasonik akan dibandingkan perbedaanya, sehingga dapat ditentukan deviasi pengukuran flow antara sensor ultrasonik dengan sensor elektromagnetik. Selain itu, nilai arus listrik pada loop sensor ultrasonik akan diperoleh dari display alat tersebut dengan konfigurasi flow-current yang berbeda. Dengan demikian karakteristik dari sensor ultrasonik dapat diperoleh dengan menganalisa menggunakan software ORIGINLAB dan Microsoft EXCEL. 
Dilanjutkan dengan melakukan perbandingan nilai aliran dari persamaan linear karakteristik sensor ultrasonik, elektromagnetik, magnetik, dan turbin.

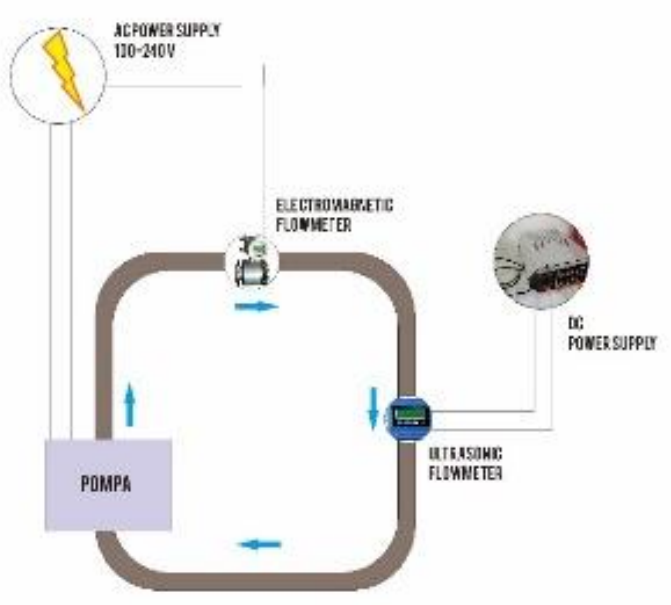

Gambar 2. Experimental setup pada untai uji BETA

\section{HASIL DAN PEMBAHASAN}

\section{Instalasi Ultrasonic Flowmeter TUF- 2000M}

Sebagai alat ukur laju aliran pada pipa, tentunya sensor harus disesuaikan dengan lingkungannya, dalam hal ini ketika sensor dipasang pada pipa tentunya harus ada parameter dari pipa yang diatur pada sensor. Parameter - parameter yang diatur pada sensor, yaitu diameter pipa $34,1 \mathrm{~mm}$, ketebalan pipa 1", bahan pipa adalah stainless steel, jenis fluida yang dialirkan pada pipa adalah air, tipe transduser adalah Clamp on-TS2, metode pemasangan transduser adalah V-method. Setelah itu pengecekan sinyal. Sinyal yang baik ada memiliki nilai lebih dari 60, dan ditandai dengan huruf "R" pada display. Kalibrasi alat ukur Ultrasonic Flowmeter TUF-2000M dan karakterisasi aliran terhadap arus listrik pada untai uji BETA. Kalibrasi dilakukan dengan mengatur frekuensi pompa dan membandingkan nilai yang ditampilkan Electromagnetic flowmeter dan Ultrasonic flowmeter. Selain itu pada saat melakukan kalibrasi, diatur pula range arus listrik yang bekerja pada sensor Ultrasonic Flowmeter. Pengkonfigurasian flowcurrent untuk 0 LPM memiliki nilai arus pada loop sensor adalah 4 $\mathrm{mA}$, sedangkan untuk titik akhir dari laju alir divariasikan mulai dari 100 LPM, 50 LPM, dan 20 LPM dengan arus pada loop sensor maksimalnya adalah $20 \mathrm{~mA}$. Maka dari itu selain mengkalibrasi ultrasonic flowmeter, didapat juga karakterisasi sensor dengan deviation error yang berbeda pula untuk setiap pengkonfigurasian laju alir. Tabel 1 hingga Tabel 3 menunjukkan hasil pengukuran laju aliran pada untai uji BETA dengan variasi frekuensi pompa menggunakan Ultrasonic Flowmeter TUF2000M dan Electromagnetic Flowmeter sebagai pembanding.

Tabel 1. Hasil kalibrasi dengan konfigurasi laju alir 0 - 100 LPM 


\begin{tabular}{|c|c|c|c|c|}
\hline F $(\mathrm{Hz})$ & $\begin{array}{c}\text { Q-EM } \\
\text { (LPM) }\end{array}$ & $\begin{array}{c}\text { Q-US } \\
\text { (LPM) }\end{array}$ & $\begin{array}{c}\text { Dev.err. } \\
(\%)\end{array}$ & $\begin{array}{c}\text { I-US } \\
(\mathrm{mA})\end{array}$ \\
\hline 0 & 0 & 0 & 0 & 4 \\
\hline 5 & 4,89 & 8,36 & $-71,18$ & 5,43 \\
\hline 10 & 12,13 & 10,47 & 13,69 & 6,01 \\
\hline 15 & 16,13 & 19,66 & $-21,89$ & 7,13 \\
\hline 20 & 25,03 & 21,82 & 12,84 & 8,06 \\
\hline 25 & 27,55 & 30,64 & $-11,22$ & 8,98 \\
\hline 30 & 36,18 & 33,28 & 8,01 & 9,78 \\
\hline 35 & 39,04 & 40,98 & $-4,99$ & 10,84 \\
\hline 40 & 44,51 & 42,54 & 4,42 & 11,23 \\
\hline 45 & 43,27 & 44,44 & $-2,72$ & 11,06 \\
\hline 50 & 45,42 & 43,81 & 3,54 & 11,42 \\
\hline
\end{tabular}

Tabel 2. Hasil kalibrasi dengan konfigurasi laju alir 0 - 50 LPM

\begin{tabular}{|c|c|c|c|c|}
\hline $\begin{array}{c}\text { F } \\
(\mathrm{Hz})\end{array}$ & $\begin{array}{c}\text { Q-EM } \\
(\text { LPM })\end{array}$ & $\begin{array}{c}\text { Q-US } \\
(\text { LPM) }\end{array}$ & $\begin{array}{c}\text { Dev.err. } \\
(\%)\end{array}$ & $\begin{array}{c}\text { I-US } \\
(\mathrm{mA})\end{array}$ \\
\hline 0 & 0 & 0 & 0 & 4 \\
\hline 5 & 4,87 & 5,55 & $-13,99$ & 5,72 \\
\hline 10 & 10,47 & 11,18 & $-6,72$ & 7,71 \\
\hline 15 & 16,18 & 16,41 & $-1,38$ & 9,32 \\
\hline 20 & 21,86 & 21,20 & 3,00 & 10,58 \\
\hline 25 & 27,67 & 27,48 & 0,70 & 12,84 \\
\hline 30 & 33,15 & 33,29 & $-0,41$ & 14,77 \\
\hline 35 & 38,94 & 36,88 & 5,28 & 16,05 \\
\hline 40 & 42,52 & 45,37 & $-6,71$ & 18,15 \\
\hline 45 & 43,28 & 44,24 & $-2,21$ & 18,82 \\
\hline 50 & 43,76 & 44,15 & $-0,88$ & 18,33 \\
\hline
\end{tabular}

Tabel 3. Hasil kalibrasi dengan konfigurasi laju alir 0 - 20 LPM

\begin{tabular}{|c|c|c|c|c|}
\hline $\begin{array}{c}\text { F } \\
(\mathrm{Hz})\end{array}$ & $\begin{array}{c}\text { Q-EM } \\
(\text { LPM) }\end{array}$ & $\begin{array}{c}\text { Q-US } \\
(\text { LPM) }\end{array}$ & $\begin{array}{c}\text { Dev.err. } \\
(\%)\end{array}$ & $\begin{array}{c}\text { I-US } \\
(\mathrm{mA})\end{array}$ \\
\hline 0 & 0 & 0 & 0 & 4 \\
\hline 5 & 4,89 & 4,35 & 11,04 & 7,29 \\
\hline 6 & 5,99 & 6,06 & $-1,21$ & 8,42 \\
\hline 7 & 7,11 & 7,41 & $-4,16$ & 9,53 \\
\hline 8 & 8,25 & 8,59 & $-4,05$ & 11,15 \\
\hline 9 & 9,33 & 9,99 & $-6,97$ & 11,82 \\
\hline 10 & 10,47 & 10,65 & $-1,74$ & 12,41 \\
\hline 11 & 11,54 & 11,63 & $-0,76$ & 13,25 \\
\hline 12 & 12,77 & 12,86 & $-0,73$ & 14,53 \\
\hline 13 & 13,83 & 13,37 & 3,34 & 14,69 \\
\hline 14 & 15,02 & 14,56 & 3,06 & 14,86 \\
\hline 15 & 16,04 & 15,50 & 3,32 & 16,26 \\
\hline 16 & 17,28 & 16,07 & 6,99 & 17,09 \\
\hline 17 & 18,21 & 17,32 & 4,92 & 17,24 \\
\hline 18 & 19,61 & 19,02 & 2,97 & 18,66 \\
\hline 19 & 20,72 & 20,18 & 2,60 & 20,00 \\
\hline
\end{tabular}

Dari hasil pengukuran diperoleh nilai deviasi untuk konfigurasi laju alir pertama adalah
$6,32 \%$, konfigurasi laju alir kedua adalah 2,12\% dan konfigurasi laju alir ketiga adalah $1,16 \%$. Dari data yang diperoleh bahwa semakin rapat konfigurasi flow-current maka nilai Dev.err. akan semakin mengecil. Hal ini bisa disebabkan karena sensor tidak ditempatkan dalam satu pipa yang sama, selain itu rangkaian dari masing - masing pun berbeda, dan juga tipe dari flowmeter yang digunakan dan yang dijadikan sebagai kalibrator berbeda yang mengartikan bahwa cara kerja dari kedua alat tidaklah sama, untuk sensor ultrasonic flowmeter yang digunakan adalah jenis sensor dengan mendeteksi pergeseran waktu (time shifting) karena laju aliran pada pipa, sedangkan untuk electromagnetic flowmeter adalah jenis sensor y dengan menggunakan Hukum Faraday untuk mendeteksi adanya induksi elektromagnetik yang diakibatkan oleh fluida yang mengalir pada pipa.

Selain itu, pada saat pengukuran didapat juga nilai arus listrik pada loop sensor ultrasonic flowmeter. Setelah diproses dengan menggunakan software OriginLAB, didapat hasil grafik karakterisasi laju aliran fluida dengan arus listrik yang bekerja pada loop Ultrasonic Flowmeter TUF-2000M. 


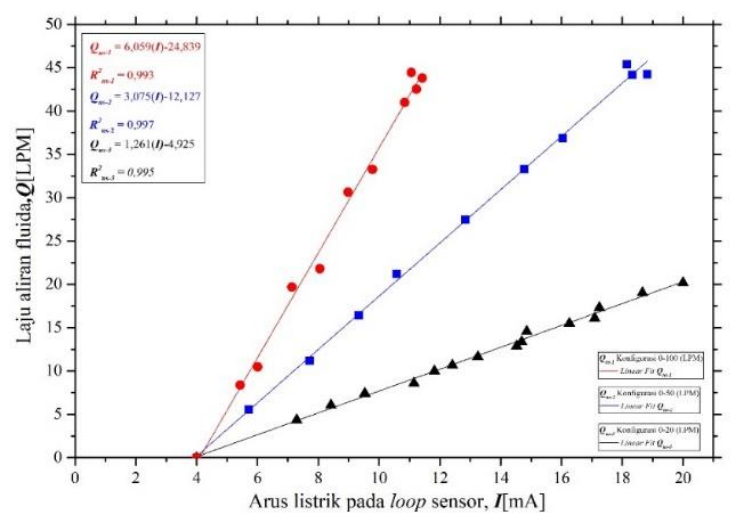

Gambar 3. Karakteristik penggabungan dari tiap konfigurasi laju alir

\section{Perbandingan Karakteristik Flowmeter}

Persamaan linear karakteristik dari sensor ultrasonik yang akan digunakan adalah persamaan dengan nilai deviasi paling rendah.
Persamaan tersebut akan dibandingkan dengan persamaan linear karakteristik sensor lainnya, pada Tabel 4. adalah persamaan linear karakteristik flow terhadap arus listrik pada loop sensor yang akan dibandingkan. Setelah itu persamaan linear tersebut dimasukan nilai I dari 4-20 mA. Dengan demikian, nilai $\boldsymbol{Q}$ dapat dilihat pada Tabel 5.

Tabel 4. Persamaan linear karakteristik flow terhadap arus listrik untuk berbagai macam sensor yang berbeda

\begin{tabular}{|c|c|c|c|}
\hline Jenis Sensor & $\begin{array}{l}\text { Laju alir } \\
\text { (LPM) }\end{array}$ & Per sa maan Kar akteristik & $\begin{array}{c}\text { Koefisien } \\
\text { Kore hsi } R^{2}\end{array}$ \\
\hline $\begin{array}{l}\text { Twrbine (wheel) } \\
\text { Flowme tr } \\
\text { FLR 1009ST-I }\end{array}$ & $0-0,5$ & $Q=31,25(\mathrm{I})-129,05$ & 0,908 \\
\hline $\begin{array}{l}\text { Ulorasonic Flowmeter } \\
\text { TUF-2000M }\end{array}$ & $0-20$ & $\mathrm{Q}=1,261(\mathrm{I})-4,925$ & 0,995 \\
\hline $\begin{array}{l}\text { Magnetic Flowmeter } \\
\text { FMG-3002 }\end{array}$ & $0-160$ & $Q=10,056(I)-39,404$ & 0,998 \\
\hline $\begin{array}{l}\text { Electromagnetik } \\
\text { Flowmes } \\
\text { Autoflow E-Mag }\end{array}$ & $0-160$ & $Q=9,169$ (I) $-36,676$ & 1,000 \\
\hline
\end{tabular}

Tabel 5. Hasil perhitungan nilai flow $Q$ dengan memasukan variabel $I$

\begin{tabular}{|c|c|c|c|c|c|c|c|}
\hline No & $\begin{array}{c}Q_{E M} \\
\text { interpolasi } \\
\text { (LPM) }\end{array}$ & $\begin{array}{c}Q_{M a g} \\
\text { interpolasi } \\
\text { (LPM) }\end{array}$ & $\begin{array}{c}Q_{\text {wheel }} \\
\text { ekstrapolasi } \\
\text { (LPM) }\end{array}$ & $\underset{(\mathbf{L P M})}{Q_{U S}}$ & $\begin{array}{c}\text { Deviasi } \\
Q_{U S-} Q_{E M} \\
(\%)\end{array}$ & $\begin{array}{c}\text { Deviasi } \\
Q_{U S-} Q_{M a g} \\
(\%)\end{array}$ & $\begin{array}{c}\text { Deviasi } \\
Q_{\text {Wheel }} Q_{U S} \\
(\%)\end{array}$ \\
\hline 1 & 0 & 0,817 & 0,619 & 0,119 & 100 & 586,555 & 420,230 \\
\hline 2 & 1,250 & 2,074 & 1,896 & 1,380 & 9,397 & 50,281 & 37,426 \\
\hline 3 & 2,501 & 3,331 & 3,174 & 2,641 & 5,315 & 26,117 & 20,177 \\
\hline 4 & 3,751 & 4,588 & 4,451 & 3,902 & 3,871 & 17,571 & 14,077 \\
\hline 5 & 5,001 & 5,845 & 5,729 & 5,163 & 3,132 & 13,200 & 10,956 \\
\hline 6 & 6,252 & 7,101 & 7,006 & 6,424 & 2,684 & 10,545 & 9,061 \\
\hline 7 & 7,502 & 8,358 & 8,283 & 7,685 & 2,382 & 8,761 & 7,788 \\
\hline 8 & 8,752 & 9,615 & 9,561 & 8,946 & 2,166 & 7,480 & 6,873 \\
\hline 9 & 10,003 & 10,872 & 10,838 & 10,207 & 2,003 & 6,515 & 6,185 \\
\hline 10 & 11,253 & 12,129 & 12,116 & 11,468 & 1,876 & 5,763 & 5,648 \\
\hline 11 & 12,503 & 13,386 & 13,393 & 12,729 & 1,774 & 5,159 & 5,217 \\
\hline 12 & 13,754 & 14,643 & 14,670 & 13,990 & 1,690 & 4,665 & 4,864 \\
\hline 13 & 15,004 & 15,900 & 15,948 & 15,251 & 1,621 & 4,252 & 4,570 \\
\hline 14 & 16,254 & 17,156 & 17,225 & 16,512 & 1,562 & 3,902 & 4,320 \\
\hline 15 & 17,504 & 18,413 & 18,503 & 17,773 & 1,511 & 3,602 & 4,106 \\
\hline 16 & 18,755 & 19,670 & 19,780 & 19,034 & 1,467 & 3,342 & 3,920 \\
\hline 17 & 20,005 & 20,927 & 20,715 & 20,295 & 1,428 & 3,114 & 2,068 \\
\hline \multicolumn{5}{|c|}{ Rata - rata deviasi } & 8,464 & 44,754 & 33,382 \\
\hline
\end{tabular}


Tabel 6. Hasil Interpolasi dan Ekstrapolasi Data flow dari sensor

\begin{tabular}{|r|r|r|r|r|}
\hline$I$ (m.A) & $\mathbf{Q}_{\mathbf{M}}$ (LPM) & $\mathbf{Q}_{\text {waut }}$ (LPM) & $\mathbf{Q}_{\mathbf{m}}$ (L.PM) & \multicolumn{1}{c|}{$\mathbf{Q}_{\mathbf{s}}$ (LPM) } \\
\hline 4 & 0 & $-4,05$ & 0,817 & 0,119 \\
\hline 5 & 9,169 & 27,2 & 10,872 & 1,38 \\
\hline 6 & 18,338 & 58,45 & 20,927 & 2,641 \\
\hline 7 & 27,507 & 89,7 & 30,982 & 3,902 \\
\hline 8 & 36,676 & 120,95 & 41,037 & 5,163 \\
\hline 9 & 45,845 & 152,2 & 51,092 & 6,424 \\
\hline 10 & 55,014 & 183,45 & 61,147 & 7,685 \\
\hline 11 & 64,183 & 214,7 & 71,202 & 8,946 \\
\hline 12 & 73,352 & 245,95 & 81,257 & 10,207 \\
\hline 13 & 82,521 & 277,2 & 91,312 & 11,468 \\
\hline 14 & 91,69 & 308,45 & 101,367 & 12,729 \\
\hline 15 & 100,859 & 339,7 & 111,422 & 13,99 \\
\hline 16 & 110,028 & 370,95 & 121,477 & 15,251 \\
\hline 17 & 119,197 & 402,2 & 131,532 & 16,512 \\
\hline 18 & 128,366 & 433,45 & 141,587 & 17,773 \\
\hline 19 & 137,535 & 464,7 & 151,642 & 19,034 \\
\hline 20 & 146,704 & 495,95 & 161,697 & 20,295 \\
\hline
\end{tabular}

Bila dilihat nilai flow berdasarkan kenaikan arus akan berbeda karena konfigurasi flow-current dari masing masing alat berbeda. Dengan demikian, untuk nilai flow_dengan menggunakan persamaan linear karakteristik dari sensor elektromagnetik, dan magnetik di interpolasi pada saat \pm 20 LPM agar dapat dibandingkan dengan karakteristik dari sensor ultrasonik. Sedangkan untuk sensor turbin (wheel), data tersebut di ekstrapolasi hingga didapatkan \pm 20.000 mLPM atau \pm 20 LPM. Setelah didapat karakteristik dari tiap sensor, dan faktor korelasi $\boldsymbol{R}^{2} \approx 1$, maka data diolah untuk mendapatkan perbandingan dengan flowmeter ultrasonik. Apabila dilihat pada Tabel 5.6, nilai deviasi paling rendah pada saat flowmeter ultrasonik dibandingkan dengan flowmeter elektromagnetik dengan nilai $8,464 \%$. Namun, perbandingan dengan flowmeter magnetik dan wheel memiliki deviasi yang sangat besar. Hal ini dikarenakan

data

yang diinterpolasi/ekstrapolasi terlalu sedikit, walaupun persamaan linear karakteristik dari tiap flowmeter memiliki nilai koefisien korelasi yang hampir mendekati 1. Selain itu, cara kerja dari masing - masing sensor adalah berbeda dan tingkat kesensitifan ketika adanya aliran pun tidaklah sama. Untuk melihat kelinearitasan dari tiap - tiap flowmeter maka dibuat grafik pada Gambar 5.

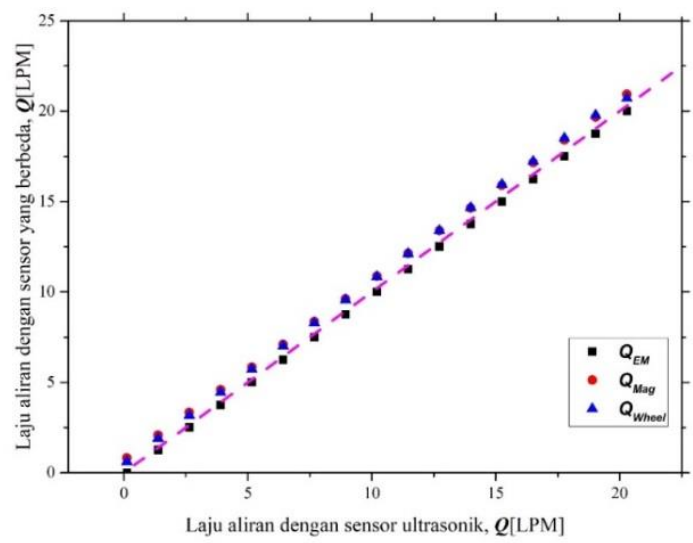

Gambar 3. Perbandingan antara $Q_{U S}$ dengan $\boldsymbol{Q}$ sensor lainnya 


\section{KESIMPULAN}

Ultrasonic Flowmeter TUF-2000M telah dikalibrasi dengan 3 konfigurasi laju alir yaitu 0 - 100, 0 - 50, dan 0 - 20 LPM. Masing - masing konfigurasi memiliki deviasi 6,32 \%, 2,12 \%, dan 1,16\%. Karakteristik dari Ultrasonic Flowmeter TUF-2000M terhadap arus listrik yang bekerja pada loop sensor didapatkan dengan menggunakan persamaan linear karakteristik yang memiliki deviasi $1,16 \%$. Persamaan tersebut adalah $\boldsymbol{Q}_{\boldsymbol{U}}=1,261(I)-4,925$ dengan koefisien korelasi $\boldsymbol{R}^{2}=0,995$ dan dibandingkan dengan flowmeter lainnya. Perbandingan antar flowmeter dilakukan dengan menginterpolasikan / mengekstrapolasikan data dari flowmeter elektromagnetik, magnetik, dan turbin sehingga konfigurasi flow-currentnya 0-20 (LPM). Dengan hasil tersebut didapatkan nilai deviasi untuk $\boldsymbol{Q}_{\boldsymbol{U}}-\boldsymbol{Q}_{\boldsymbol{E} \boldsymbol{M}}$ adalah $8,464 \%$, deviasi untuk $\boldsymbol{Q}_{\boldsymbol{U}}-\boldsymbol{Q}_{\mathbf{M a g}}$ adalah 44,754 \%, dan deviasi untuk $\boldsymbol{Q}_{\text {Wheel }} \boldsymbol{Q}_{\boldsymbol{U}}$ sebesar 33,382 $\%$.

\section{UCAPAN TERIMAKASIH}

Terima kasih kepada Kepala PTKRN BATAN atas kebaikan dan izinnya untuk memberikan kami kesempatan melaksanakan magang ilmiah. Terima kasih juga kepada para staf PTKRN BATAN yang telah mendukung kegiatan ini. Kegiatan ini didanai oleh KEMENRISTEKDIKTI melalui Program INSINAS Pratama Kemitraan 2018 antara PTKRN BATAN dan FTUI.

\section{DAFTAR PUSTAKA}

1. M. HOLT, R. J. CAMPBELL, M. B. NIKITIN, "Fukushima Nuclear Disaster". Congressional Research Service 7-5700, 2012

2. M. JUARSA, A. R. ANTARIKSAWAN dkk. Estimation of Natural Circulation FLow Based on Temperature in the FASSIP-02 Large-Scale Test Loop, Facility, The 2nd International Tropical Energy Conference (i-TREC) 2017 Bali-Indonesia 3-4 October 2017 (published in IOP Conf. Series: Earth and Environmental Science 105 (2017)).

3. R. ANTARIKSAWAN, S. WIDODO, M. JUARSA, DEDY HARYANTO, M. H. KUSUMA,NANDY PUTRA, Numerical study on natural circulation characteristics in FASSIP-02 experimental facility using RELAP5code, The 2nd International Tropical Renewable Energy, BaliIndonesia 3-4 October 2017 (published in IOP Conf.Series: rth and Environmental Science 105 (2017)).

4. M. MISALE, et al., Some Considerations On The Interaction Between The Fluid And Wall Tube 
During Experiments in a Single-Phase

Natural Circulation Loops. Proceedings of The 3rd IASME/WSEAS Int. Conf. on Heat Transfer, Thermal Engineering and Environment 128, 2005.

5. YORAM, Z. A Review Of Natural Circulation Loops in Pressurized Water Reactors and Other Systems. NorthHolland. Nuclear Engineering and Design 67, 1981, 203-225

6. HAKIM, FAISAL NUR, Estimasi Laju Aliran Sirkulasi Alam Untai FASSIP-02 Berdasarkan Variasi Temperature WHT dan WCT Menggunakan MATLAB, 2018.

7. JUARSA, MULYA dkk. Analisis Aliran Sirkulasi Alamiah Dengan Bilangan Reynolds Berdasarkan Variasi Sudut Kemiringan Untai Simulasi Sirkulasi Alamiah. ISBN 978-979-97986-6-4

8. User Manual TUF-2000M

9. MAULANA, RESTIYA, Karakterisasi Flowmeter FLR 1009ST-I Dengan Menggunakan Kalibrator JOFRA Dan Modul NI Yang Digunakan Pada Untai uji Keselamatan PLTN FASSIP-02, STT-PLN, 2017, Jakarta. 